\title{
Primary Fixation of AO Type-C Fracture of the Distal Radius with Volar Locking Plates. A Cross-Sectional Study of Patient Rated Outcomes at Hospital Tengku Ampuan Afzan
}

\author{
Mohd Sallehuddin H, Zamzuri Z, Ariff MS, Mohd Shukrimi A, Mohamed Azril MA, Nazri MY
}

\begin{abstract}
Department of Orthopaedics, Traumatology and Rehabilitation, Kulliyyah of Medicine, International Islamic University Malaysia
\end{abstract}

\begin{abstract}
Introduction: This is a cross-sectional study of 37 patients with AO type C (complete intra-articular) fractures of the distal radius, evaluating the functional, anatomical, and patient rated outcomes one year after primary fixation with a volar locking plate. Methods: Functional outcomes were assessed based on the grip strength, and the range of motion of forearm and wrist. Anatomical outcomes were assessed based on the radial inclination, radial height, volar tilt, and articular step or gap. Patient rated outcome was measured with a Disability of arm, shoulder and hand (DASH) questionnaire. Results: One year after surgery, 24 (64\%) patients achieved good and excellent anatomical results, and DASH scores were acceptable in $73 \%$ of patients. Most of the patients had achieved $80 \%$ of their grip strength. The mean DASH score of 12.3 was comparable with other studies. Grip strength, radial inclination and volar tilt had a significant correlation with the DASH score. Conclusion: Volar locking plates can be used to achieve optimal reduction in all three parameters in the treatment of $\mathrm{AO}$ type $\mathrm{C}$ fractures of the distal radius. Versatile fracture fragment reduction and angular stability enable rehabilitation hence obtaining good functional outcomes.
\end{abstract}

KEYWORDS: AO type C distal radius fractures, velar locking plate, DASH score, functional outcome, anatomical outcome

\section{INTRODUCTION}

The incidence of distal end radius fracture is estimated around 19-43 per 10000 people annually. ${ }^{1}$ The age distribution is divided into two extreme groups; the young being commonly involved in motor vehicle accidents, and the older group with a common incidence of falls at home. Treatment options vary depending on the severity of the fracture. Simple fractures such as those which are extra-articular and minimally displaced can be treated conservatively. However, there is a risk of early loss of reduction. Hence, such cases require early and regular followup. Unstable fractures are best treated surgically. In AO type C (intra-articular) fractures of the distal radius, achieving anatomical reduction and stable fracture fixation are essential because of the

Corresponding author:

AP Dr. Zamzuri B. Zakaria @ Mohamad Department of Orthopaedics, Traumatology and Rehabilitation,

Kulliyyah of Medicine, International Islamic University Malaysia, Jalan Sultan Ahmad Shah, Bandar Indera Mahkota, 25200 Kuantan, Pahang, Tel. No. 013-9906744

Fax No. 09-5144451

Email: zamdr@yahoo.co.uk functional implications for the wrist joint. Fracture fixation with a volar locking plate is an option with excellent clinical and radiological outcomes. ${ }^{2}$ The volar and dorsal fragments can be supported from the volar side of the distal radius, with the ability to hold the fracture fragments securely without crossing the wrist joint. Thus, early mobilization can be started as early as two days following surgery without secondary reduction loss ensuring good functional outcome. ${ }^{3}$ The aim of this study was to evaluate the functional, anatomical and patient rated outcomes of $\mathrm{AO}$ type $\mathrm{C}$ fracture of the distal radius treated primarily with a volar locking plate.

\section{MATERIALS AND METHODS}

This cross sectional study was performed by reviewing patients and records of patients who had been admitted for closed comminuted intra-articular fractures of the distal end of radius and treated with a volar locking plate in Tengku Ampuan Afzan Hospital, Kuantan from January 2011 until June 2012. Inclusion criteria were; patients 18 years and above with closed $\mathrm{AO}$ type $\mathrm{C}$ fractures of the distal radius treated with a volar locking plate within 28 days after injury, who had attended regular follow ups and completed at least one year follow up. Exclusion criteria were patients who sustained open fractures, patients who sustained other injuries to the ipsilateral limb and previous trauma to the limb with residual deformity and dysfunction. The A.O. classification of the distal radius fracture was used based on the true 
anteroposterior and lateral wrist radiograph on admission; type C1 (simple intra-articular and metaphyseal fracture), type C2 (simple intra-articular with metaphyseal multifragmentary) and type C3 (multifragmentary intra-articular and metaphyseal). The functional and anatomical outcomes were assessed one year following surgery. The functional outcome evaluation consisted of measurement of grip strength with a Jamar dynamometer, wrist flexion, extension, radial and ulnar deviation, and forearm supination and pronation. The patient rated outcomes were evaluated using the Disability of Arm, Shoulder and Hand questionnaire (DASH) score at one year follow up. This questionnaire consists of 30 questions; 21 questions evaluated the ability to perform specific physical activities, five questions evaluated symptom severity, and another four questions evaluated the effect to social activities, self-image, work and sleep. The acceptable score was less than 15 and more than 15 was deemed unacceptable. ${ }^{4}$ With this, the patients were divided into two groups for statistical analysis, which were; acceptable functional outcome (score less than 15) and unacceptable functional outcome (score more than 15). The mean of the DASH score was compared with other studies.

Anatomical outcomes included radial height, radial inclination, volar tilt and articular surface gap, measured on the anteroposterior and lateral view of wrist radiograph at one-year post surgery. The outcomes were graded as excellent, good, fair and poor based on the criteria by Jakim et al. ${ }^{5}$ The scoring criteria are summarized in Table I. Data was analysed using the Spearman correlation analysis with SPSS software version 20 . Statistical significance was taken at $\mathrm{p}<0.05$.

\section{RESULTS}

There were 41 cases of closed comminuted fractures of the distal end of radius treated with variable angle volar locking plate of which 37 patients were available for the study; twenty-nine (78\%) male patients and eight (22\%) females with ages ranging from 17 to 67 years. The most common mechanism of injury was due to motor vehicle accident (73\%). Eight cases (22\%) were classified as AO type C1, 16 cases (43\%) type C2 and 13 cases (35\%) as type C3.

Table I. Anatomical scoring method of closed comminuted fracture distal end of radius based on Jakim et al ${ }^{4}$

\begin{tabular}{|c|c|c|}
\hline \multicolumn{2}{|l|}{ Radiological Scoring } & Score \\
\hline \multirow[t]{4}{*}{ Radial angle $\left({ }^{\circ}\right)$} & $23-18$ & 30 \\
\hline & $17-13$ & 24 \\
\hline & $12-10$ & 18 \\
\hline & Less than 10 & 00 \\
\hline \multirow[t]{4}{*}{ Radial length (mm) } & $13-10$ & 40 \\
\hline & $9-7$ & 32 \\
\hline & $6-5$ & 24 \\
\hline & Less than 5 & 00 \\
\hline \multirow[t]{4}{*}{ Volar tilt $\left({ }^{\circ}\right)$} & $11-7$ & 30 \\
\hline & $6-3$ & 24 \\
\hline & $2-0$ & 18 \\
\hline & Negative & 00 \\
\hline \multirow[t]{2}{*}{ Incongruency (mm) } & $1-2$ & -10 \\
\hline & Greater than 2 & -20 \\
\hline \multirow{3}{*}{ Radio-ulnar joint } & Less than 2 with fragment rotation & -30 \\
\hline & Subluxation & -05 \\
\hline & Dislocation & -10 \\
\hline
\end{tabular}

\section{$\underline{\text { Anatomical results }}$}

At one year, 15 (40\%) cases were graded as excellent, nine (24\%) cases as good, eight (22\%) cases as fair, and five (14\%) cases as poor anatomical outcome (Table II). 
Table II. Anatomical results of closed comminuted fracture of the distal end of radius treated with a volar locking plate according to Jakim et al. ${ }^{5}$

\begin{tabular}{lllll}
\hline Outcome & Excellent & Good & Fair & Poor \\
\hline Patients/percentage & $15(40 \%)$ & $9(24 \%)$ & $8(22 \%)$ & $5(14 \%)$ \\
\hline
\end{tabular}

Anatomical score: Excellent $=100-90$, Good $=89-80$, Fair $=79-70$, Poor $=<70$.

Functional results

Most of the patients achieved $80 \%$ of their grip strength compared to the contralateral side one year after surgery, with the mean of $25.1 \pm 7.8 \mathrm{~kg}$. Table III summarizes the range of motions of the wrist achieved at oneyear review.

Table III. The mean of functional outcome parameters in one-year assessment, values expressed in mean and standard deviation.

\begin{tabular}{lll}
\hline Functional outcome parameters & Range of motions & Mean Value \\
\hline
\end{tabular}

Grip strength $(\mathrm{kg})$

Wrist flexion $\left({ }^{\circ}\right)$

Wrist extension $\left({ }^{\circ}\right)$

Supination $\left({ }^{\circ}\right)$

Pronation $\left({ }^{\circ}\right)$

Radial deviation $\left({ }^{\circ}\right.$ )

Ulnar deviation $\left({ }^{\circ}\right)$

-
$30-70$
$40-90$
$60-90$
$45-82$
$10-40$
$20-55$

$25.1 \pm 7.8$

$58.1 \pm 10.3$

$63.9 \pm 10.2$

$74.3 \pm 7.4$

$63.5 \pm 9.1$

$23.8 \pm 6.0$

$32.2 \pm 8.6$

\section{Patient rated outcome results}

The mean DASH score at one year was $12.3 \pm 4.2$. Twenty-seven (73\%) cases had acceptable scores and 10 patients $(27 \%)$ had non-acceptable scores. The correlation of anatomical parameters and functional parameters with the DASH score was analysed using a Spearman correlation analysis. The significant correlations were radial inclination, volar tilt and grip strength. The radial inclination $(r=-0.366, p=0.03)$, volar tilt $(r=-0.47, p=0.01)$ and grip strength $(r=$ $-0.348, p=0.03$ ) showed weak, negative correlations toward the DASH score.

\section{DISCUSSION}

Fractures of the distal end of radius are among the common cases encountered in casualty encompassing one sixth of the trauma cases reviewed. ${ }^{6}$ Comminuted fractures of the distal end of radius were previously treated by either cast application, external fixation with supplementary $\mathrm{K}$ wires or internal fixation with a volar plate. ${ }^{7}$ Volar plating is superior compared to external fixator as it gives a better radial inclination and volar tilt. ${ }^{8}$ Even though volar plating resulted in a better radiological outcome, assessment of functional outcome at one-year post fixation was not significantly different. ${ }^{6}$ A meta-analysis of 12 studies comparing the outcome of external fixator or internal fixation with volar plate as the treatment for fracture distal end radius revealed a better functional outcome provided by volar plate fixation, as evaluated by DASH score, better forearm supination and restoration of volar tilt. However, external fixation resulted in a better grip strength. ${ }^{9}$

Whether good radiological outcome correlates with good functional outcome is debatable. Several studies have shown that the radiological parameters did not affect the functional outcome. ${ }^{4,6,8}$ On the other hand, other studies have shown the importance of achieving radiological parameters reduction to attain the optimal functional outcome. ${ }^{2,3,7}$ Better radial inclination, radial height and volar tilt was achieved with volar plate and associated with better DASH score compared to external fixation for distal end radius fracture. ${ }^{10}$

This study showed that radial inclination was the only significant factor in determining acceptable DASH score. The radial inclination and volar tilt showed a weak negative correlation to DASH score. Therefore, optimal radial inclination and volar tilt would result in a lower DASH score, hence, a better functional outcome. However, cumulative scoring of parameters obtained by the Jakim radiological scoring system showed no significant difference between the subgroup of excellent, good, fair and poor to the acceptable or non-acceptable DASH score. Sixty-four percent of our patients had good and excellent anatomical outcome compared to the study published by Othman et al. who had $76.4 \%$ of good and excellent anatomical outcome. ${ }^{11}$ Grip strength as measured by JAMAR dynamometer revealed mean grip strength of $25.1 \mathrm{~kg}$ and $80 \%$ of grip strength was achieved at one year post-surgery. This also revealed a weak negative correlation towards 
DASH score. The stronger the grip strength gave a lower DASH score and a better patient perception and functional outcome.

At one year, this study revealed the mean DASH score of 12.3 and $73 \%$ of the patients had acceptable patient rated outcome at one-year follow up. The result was comparable to other previous studies. Hakimi et al. reported a mean DASH score of 14.8 for 77 patients at one year post-surgery. ${ }^{12}$ Two other studies reported mean DASH scores between 11.0 and 12.0 at two years' post-surgical review. ${ }^{13,14}$

\section{CONCLUSION}

Regarding primary fixation of $\mathrm{AO}$ type $\mathrm{C}$ distal radius fractures, patient rated outcome using DASH score revealed radial inclination is the only significant determining factor of an acceptable DASH score. Optimal radial inclination and volar tilt produce a better functional outcome. Good functional outcome and better patient perception were also observed with a stronger the grip strength. However, cumulative radiological scoring did not show any correlation with the overall functional outcome. The volar locking plate can achieve versatile fracture fragment reduction and angular stability to initiate rehabilitation. Hence, all three parameters can be obtained optimally.

\section{REFERENCES}

1. Abramo A, Kopylov P, Geijer M, Tagil M. Open reduction and internal fixation compared to closed reduction and external fixation in distal radial fractures: a randomized study of 50 patients. Acta Orthop 2009; 80:478-85.

2. Tarallo L, Adani R, Mugnai R, Catani F. The treatment of distal radius articular fractures of C1-C2 type with DVR plate: analysis of 40 cases. Musculoskelet Surg 2011; 95:225-30.

3. Konstantinidis L, Helwig P, Strohm P, et al. Clinical and radiological outcomes after stabilization of complex intra-articular fractures of the distal radius with volar $2.4 \mathrm{~mm}$ LCP. Arch Orthop Trauma Surg 2010; 130:751-7.

4. Phadnis J, Trompeter A, Gallagher K, et al. Mid-term functional outcome after the internal fixation of distal radius fractures. J Orthop Surg Res 2012; 7:4-7.

5. Jakim I, Pieterse HS, Sweet MBE. External fixator for intraarticular fractures of the distal radius. J Bone Joint Surg Br 1991; 73:302-6.

6. Zamzuri Z, Yusof M, Hyzan MY. External fixation versus internal fixation for closed unstable intra-articular fractures of the distal radius. Med Journal Malaysia 2004; 59:15-19.

7. Lam F, Jaysekera N, Karmani S, Jupiter JB. What's new in the treatment of distal radius fractures? Current orthopaedics 2006; 20:208-11.

8. Suarez-Arias L, Cecilia-Lopez D. Functional and radiological outcomes in distal radius fractures treated with a volar plate vs an external fixator. Revista espanola de cirugia ortopedica y traumatologia (English edition) 2009; 53:98-105.

9. Wei DH, Poolman RW, Bhandari M, Wolfe VM, Rosenwasser MP. External fixation versus internal fixation for unstable distal radius fractures. A systematic review and meta analysis of comparative clinical trials. J Orthop Trauma 2012; 26:386-94.

10. McFadyen I, Field J, Mc Cann P, et al. Should unstable extra articular distal radius fractures be treated with fixed-angle volar locked plates or percutaneous Kirschner wires? A prospective randomised controlled trial. Injury 2011; 42: 162-6.

11. Othman AY. Fixation of dorsally displaced distal radius fractures with volar plate. J Trauma 2009;66:1416-20.

12. Hakimi $M$, Jungbluth $P$, Windolf J, Wild $M$. Functional results and complications following locking palmar plating on the distal radius. $\mathrm{A}$ retrospective study. J Hand Surg Eur Vol 2010; 35:283-8.

13. Kwan K, Lau TW, Leung F. Operative treatment of distal radius fractures with locking plate - a prospective study. Int Orthop 2011; 35: 389-94.

14. Matschke $S$, Marent-Huber $M$, Audigé $L$, Wentzensen A; LCP Study Group. The surgical treatment of unstable distal radius fractures by angle stable implant: A multicenter prospective study. J Orthop Trauma 2011; 25:312-7. 